\title{
Analytical Methodology for Modelling of Circulating Current Loss in Synchronous Electrical Machines with Permanent Magnets
}

\author{
Dmitry Golovanov ${ }^{1}$ and Chris Gerada ${ }^{1,2}$ Senior Member, IEEE \\ ${ }^{1}$ Department of Electrical Engineering, University of Nottingham, Nottingham, UK \\ ${ }^{2}$ School of Engineering, University of Nottingham Ningbo, China
}

\begin{abstract}
This paper describes a novel analytical methodology for modelling winding copper losses as a result of circulating currents (CC) in permanent magnet synchronous machines (PMSM). CCs are important to be considered at an early design stage especially in high frequency and high performance machines where sub-optimal design choices can lead to significant alternating current $(\mathrm{AC})$ losses. Nowadays mainly FEM method is used for precise calculation of circulating currents. However, it suffers on significant computational time required for building models and simulation of circulating current effect that makes it inapplicable for optimization purpose. The paper demonstrates the computationally efficient methodology through comparison with FEM based models for high power density PMSM with concentrated winding and validation against experimental results for a stator section at the fundamental frequency from $500 \mathrm{~Hz}$ to $2000 \mathrm{~Hz}$. The methodology allows simulation of CC and AC Ohmic losses when machine supplied by any current waveforms, for arbitrary size and location of the conductors in the slots. A key novelty of the proposed method is the utilization of subdomain (SDM) approach in conjunction with solution of a system of ordinary differential equations (ODE) for an equivalent electrical circuit of machine windings. This approach is precise and fast but has never been used before for circulating current loss evaluation in windings of electrical machines. The model is intended to be used at the design stage of an electrical machine where multiple geometric dimensions, winding configurations and conductor placement in the slot are considered towards an optimal design.
\end{abstract}

Index Terms - Analytical model, circulating current loss, AC loss in electrical machines

$\begin{array}{ll}R_{S 1}, R_{S 2} . R_{S n} & \text { Strands resistance } \\ L_{S 1}, L_{S 2} . L_{S n} & \text { Strands inductance } \\ E_{1}, E_{2} . E_{n} & \text { bEMFs induced in strands } \\ {\left[M_{s t r}\right]} & \text { Square } \times \mathrm{n} \text { strands inductance matrix } \\ {\left[M_{p h}\right]} & \text { Rectangular } \mathrm{n} \times \mathrm{x} \text { matrix of mutual inductances } \\ & \text { between machine phases and each strand of } \\ & \text { investigated coil, } \mathrm{x}-\text { number of phases } \\ {[R]} & \text { Resistance matrix } \\ I_{1} . . I_{n} & \text { Current through each strand } \\ I_{p h_{-} 1} . I_{p h} x & \text { Phase current } \\ n & \text { Number of parallel strands per coil } \\ U & \text { Voltage across the terminals of stranded coil } \\ A_{g} & \text { Vector potential in the air gap } \\ A_{s o} & \text { Vector potential in the slot opening } \\ A_{s} & \text { Vector potential in the slots with bulk coils } \\ A_{P M} & \text { Vector potential in the PM subdomain } \\ A_{t p}, A_{J}, A_{b t} & \text { Vector potentials in the slots with stranded coils } \\ A_{q}^{P M}, B_{q}^{P M}, C_{q}^{P M}, D_{q}^{P M} & \text { Coefficients for the function of vector potential } \\ & \text { in PM subdomain }\end{array}$

\begin{tabular}{|c|c|}
\hline$A_{q}, B_{q}, C_{q}, D_{q}$ & $\begin{array}{l}\text { Coefficients for the function of vector potential } \\
\text { in the air gap }\end{array}$ \\
\hline$A_{0 s o}, B_{0 s o}, A_{k}, B_{k}$ & $\begin{array}{l}\text { Coefficients for the function of vector potential } \\
\text { in the slot opening }\end{array}$ \\
\hline$A_{0 s}, B_{0 s}, A_{m}, B_{m}$ & $\begin{array}{l}\text { Coefficients for the function of vector potential } \\
\text { in the slots with bulk coils }\end{array}$ \\
\hline $\begin{array}{l}A_{0 t p}, B_{0 t p}, A_{t p \_m}, B_{t p \_m} \\
A_{0 J}, B_{0 J}, A_{J \_m}, B_{J_{-} m} \\
A_{0 t p}, B_{0 t p}, A_{t p \_m}, B_{t p \_m}\end{array}$ & $\begin{array}{l}\text { Coefficients for the function of vector potential } \\
\text { in the slots with stranded coils }\end{array}$ \\
\hline$r, \theta$ & Radial and angular coordinates \\
\hline$q$ & $\begin{array}{l}\text { Harmonic order of vector potential for } \\
\text { permanent magnets and air gap subdomains }\end{array}$ \\
\hline$k, m$ & $\begin{array}{l}\text { Harmonic orders of vector potential for slot } \\
\text { opening and slot subdomains }\end{array}$ \\
\hline$R_{0} . . R_{4}$ & Radii of machine geometry \\
\hline$R_{\text {Jin }}^{p}, R_{\text {Jext }}^{p}, R_{\text {Jin }}^{S}, R_{\text {Jext }}^{S}$ & $\begin{array}{l}\text { Internal and external radii of probe and source } \\
\text { conductors in the stranded coils }\end{array}$ \\
\hline$Z, Z_{\text {str }}$ & $\begin{array}{l}\text { Number of slots and number of slots with } \\
\text { stranded coils }\end{array}$ \\
\hline$j$ & Number of conductors in strand \\
\hline$\alpha$ & Slot span \\
\hline$\gamma$ & Slot opening span \\
\hline B & Bulk coil span \\
\hline$\beta$ & Strand span \\
\hline$\chi$ & Angular position of conductors inside the slot \\
\hline$J_{0}$ & DC component of current density \\
\hline$J_{m}$ & $\begin{array}{l}\text { Amplitude of the } \mathrm{m}^{\text {th }} \text { harmonic of current } \\
\text { density }\end{array}$ \\
\hline$J$ & Fourier decomposition of current density \\
\hline$\theta_{1}$ & Slot angular position \\
\hline$\Delta_{1}$ & Rotor position \\
\hline s & Number of PM segments per pole pitch \\
\hline$M_{r}, M_{\theta}$ & $\begin{array}{l}\text { Radial and tangential components of the } \\
\text { magnetization vector in the PM subdomain }\end{array}$ \\
\hline$J_{m}$ & $\begin{array}{l}\text { Amplitude of the } \mathrm{m}^{\text {th }} \text { harmonic of current } \\
\text { density }\end{array}$ \\
\hline$J$ & Fourier decomposition of current density \\
\hline$\theta_{1}$ & Slot angular position \\
\hline$\Delta_{1}$ & Rotor position \\
\hline 1 & Active length \\
\hline $\mathrm{S}_{\text {cor }}$ & Conductor area \\
\hline
\end{tabular}

\section{INTRODUCTION}

CIRCULATING currents (CC) or uneven current $\checkmark$ distribution between parallel paths or conductors in armature windings of electrical machines can be significant especially when machines operate at high frequencies. The impact of circulating currents can be very harmful and should always be taken into account at design stage of electrical machines since the effect may lead to significant Ohmic loss increase and eventually to lower than expected efficiency and increase of heat load.

When estimating $\mathrm{CC}$, the machine geometry, the winding 
electrical connections as well as the parallel conductors' size and their exact location within the slot should be taken into account. With the increased availability of fast switching, widebandgap devices electrical machines are often pushed to work at very high fundamental frequencies to improve achievable power densities. These machines are particularly susceptible to AC losses and sensitive to loss density. On the other hand, advances in coil forming and winding techniques can allow for more controlled positioning of conductors in slots to minimize CC losses. Published methodologies for calculating CC loses are mainly based on detailed finite element (FEM) and Monte Carlo based methods [1], [2], [3]. Despite of high accuracy of FEM, the simulation times for such approaches are unacceptably high especially for optimization purposes due to the large number of individual conductors in slots the and the time required to generate those strands in the model that could be even higher that the computational time itself.

There are several works published on calculation of CC losses in permanent magnet synchronous machines (PMSM) and high-speed induction machine by using FEM: [4], [5], [6] and [7] where CC losses were analysed with high accuracy but the major drawback of this approach is very high computational time required (up to several hours) to perform the work. In [8], [9] and [10] methods are described for modelling CC for Roebel bars of large hydro and turbo-generators also based on FEM and therefore having the same problem of being time consuming. An analytical method based on equivalent magnetic circuit was proposed in [11] for high-speed PMSM which utilises only the fundamental air-gap harmonic for CC calculation and does not take into account the mutual inductance of parallel strands that may lead to inaccuracies. The method proposed for PMSM in [12] is considered as analytical but it still uses FEM for the calculation of the magnetic field in the slots.

In the present work an alternative analytical methodology for modelling CC loss in the windings of synchronous electrical machines is proposed taking into account the size and the arrangement of conductors in slots. The methodology has been applied for PMSM with Halbach array but conceptually can be adapted for a wide range of other machine types. This model when used for design optimization purpose: in particular for optimization of strands placement in machine slots to minimize the AC copper losses, provides significant faster simulation times compared to FEM based approaches whilst maintaining high accuracy. For instance the computational time by the proposed model for a case study described in section VII takes about $4.5 \mathrm{~min}$ compared to $30 \mathrm{~min}$ for a FEM based approach (PC hardware: Intel Xeon CPU E5-1620 v3 at 3.5 GHz, 32-GB RAM; software: MATLAB R2017a).

The novel methodology described in this work is purely analytical and can be applied to multiphase PMSM with arbitrary arrangement of the conductors in the slot and winding connections. It takes into account the design of permanent magnet (PM) Halbach array as well as the impact of the stator slot opening and high order harmonics of magnetic field in active parts of machine that were not considered in analytical models before.

\section{ASSUMPTIONS}

The proposed methodology was developed for an inner rotor (IR) PMSM with Halbach array but can be adapted for different type of machines by changing the rotor topology and its mathematical description.

The model was developed taking into account the following assumptions:

- The model is developed in polar coordinate system $(r, \theta)$ and $3 \mathrm{D}$ effects are neglected however the additional endwinding inductance of the strands is introduced into the model as a parameter and can be taken into account.

- The stator and rotor cores have an infinite magnetic permeability $\mu \rightarrow \infty$, thereby the material saturation is neglected Fig. 1.

- The magnetic properties of permanent magnets (PM) are linear and described as (1)

$$
B=\mu_{0}(H+M)
$$

where $H$ is the magnetic strength of external field, $M$ is the magnetization of PM. The magnetic permeability of PMs is equal to 1 .

- The direction of magnetization (DOM) of PMs are considered: to be ideal. Thereby the vectors $\bar{M}$ are aligned with the polar coordinate system within each PM segment.

- The strands shape is assumed to be sector geometry since all the boundaries in the model should be aligned with the polar system of coordinates. However the strands cross-section can be normalized to an equivalent round wire crosssection.

- The eddy-currents (skin and proximity) effects inside the strands are not considered.

- The armature coils of the machine are fed by a current source. The current source is assumed to have an arbitrary waveform.

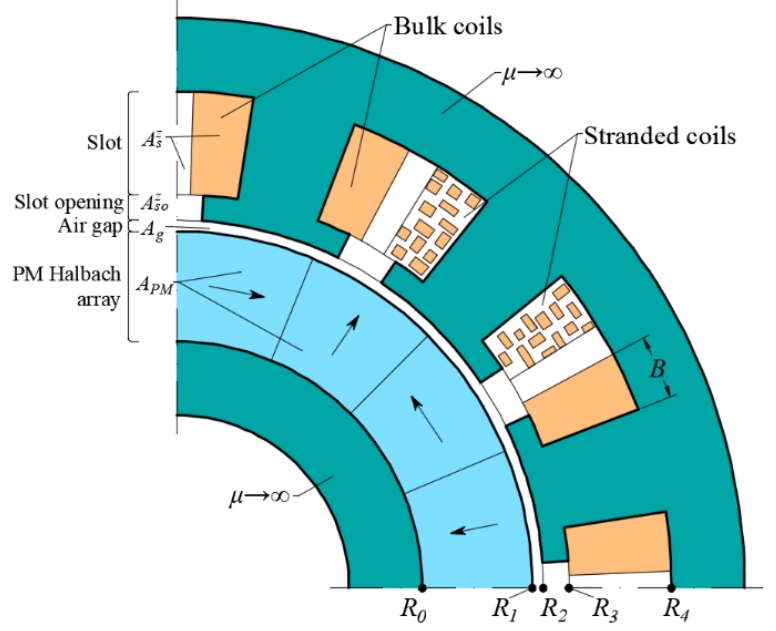

Fig. 1 The design of IR PMSM with Halbach array

Whilst the proposed methodology allows for considering all the coils of a given machine at strand level, a mixed approach where only some coils are considered at strand level and others bulked together can lead to reduced computational times without loss of accuracy. This is illustrated in Fig.1. All the coils where the $\mathrm{CC}$ is a matter of investigation needs to be considered as stranded. For instance if $\mathrm{CC}$ path covers several coils connected in series then they need to be considered as 
stranded to calculate the CC correctly. However, in the most simplest case only one coil can be considered as stranded if parallel strands of that coil are shorted at its terminals - so the CC path is localized within this coil and the CC in all the other coils are out of the scope of investigation.

\section{The METHOdOLOGY DESCRIPTION}

The main reason of uneven current distribution among parallel strands of coils of electrical machines is the difference in self and mutual inductances between the strands as well as the difference of back Electromotive Force (bEMF) induced in each strand. The difference of bEMF and inductance depends on the strand position within the slot and strand dimensions which are in turn affected by particular machine geometry. An equivalent circuit of a synchronous machine with current-fed, multiphase winding system can be represented as in Fig. 2 . Each phase of the machine can be represented as an individual circuit since the current sources predefine the phase current. The only interaction between of the phases occurs via mutual inductance. Each phase of machine may include parallel strands $S_{1}, S_{2} \ldots S_{n}$ in phase coils; where $n$ is the number of parallel strands. If the phase coils are connected in series then the parallel strands can be either joined together at the end of each coil at points A and B in Fig. 2 or they can be connected together at the phase terminals - thereby the bulk level coils in the circuit in Fig. 2 become redundant.

In this section we will first focus on the stranded coils of the circuit in Fig. 2 and the current circulating through the parallel strands $S_{1} \ldots S_{n}$. Phase 1 in Fig. 2 is presented at more detailed level: it contains the part that belongs to the stranded coils and to the bulk coils. Each coil strand has its own resistance $R_{S 1}, R_{S 2} . R_{S n}$ inductance $L_{S 1}, L_{S 2} . L_{S n}$ and induced bEMF: $E_{1}, E_{2} . . E_{n}$. At a more detailed level each strand includes a set of the conductors $C_{1} \ldots C_{m}$ connected in series; where $m$ is the number of conductors in a strand. Each conductor has its own location in the machine slot, inductance and bEMF. The strand resistance, inductance and bEMF can be written via the sum of resistance, inductance and bEMF of the appropriate set of conductors belonging to that strand. All the strands in the equivalent circuit interact with each other via mutual inductance.

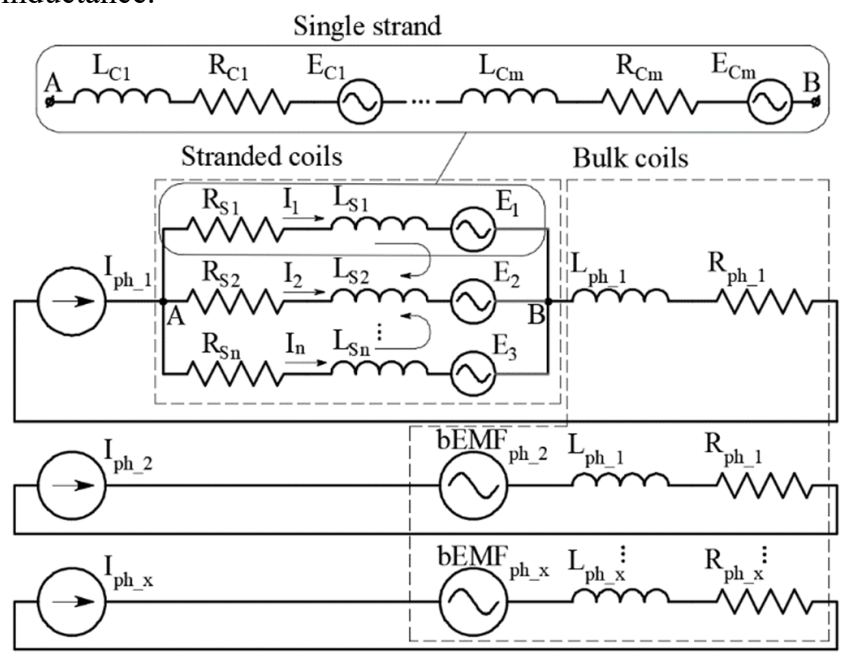

Fig. 2 Equivalent circuit
The Kirchhoff's law for a section of electrical circuit that is related to the stranded level coil Fig. 2 can be written in matrix format (2).

$$
\left\{\begin{array}{c}
{\left[M_{s t r}\right] \cdot\left[\begin{array}{c}
\frac{d I_{1}}{d t} \\
\frac{d I_{2}}{d t} \\
\vdots \\
\frac{d I_{n}}{d t}
\end{array}\right]+\left[M_{p h}\right] \cdot\left[\begin{array}{c}
\frac{d I_{p h_{-} 1}}{d t} \\
\frac{d I_{p h_{-}}}{d t} \\
\vdots \\
\frac{d I_{p h_{\_} n}}{d t}
\end{array}\right]+[R] \cdot\left[\begin{array}{c}
I_{1} \\
I_{2} \\
\vdots \\
I_{n}
\end{array}\right]=U-\left[\begin{array}{c}
E_{1} \\
E_{2} \\
\vdots \\
E_{n}
\end{array}\right]} \\
\sum I_{n}=I_{p h_{-} 1}
\end{array}\right.
$$

Where $I_{1} \ldots I_{n}$ is the current through each strand; $I_{p h_{-} 1} . I_{p h_{-} x}$ is the phase current; $E_{1} . . E_{n}$ is the bEMF induced in an appropriate strand; $\left[M_{s t r}\right]$ is the square $n \times n$ strands matrix of inductance, $\left[M_{p h}\right]$ is rectangular $n \times x$ matrix of mutual inductance between machine phases and each strand, here $x$ is a phase index; $U$ is the voltage between the terminals A-B of parallel strands; $[R]$ is the diagonal $n \times n$ resistance matrix with strands resistance $R_{1} \ldots R_{n}$. The circulating currents $I_{1} \ldots I_{n}$ can be found as the result of solution of the system of ordinary differential equations (ODE) (2). To solve this system we have to define the inductance matrix $\left[M_{s t r}\right]$, the mutual inductance matrix $\left[M_{p h}\right]$ and the vector of strands bEMF over one electrical period. The matrix $\left[M_{s t r}\right]$ has a structure (3). The main diagonal of $\left[M_{s t r}\right]$ is the vector of strands self-inductance while all the other elements are the mutual inductances of the strands.

$$
M_{s t r}=\left[\begin{array}{ccc}
L_{1} & \cdots & M_{1 \_n} \\
\vdots & \ddots & \vdots \\
M_{n_{-} 1} & \cdots & L_{n}
\end{array}\right]
$$

The mutual inductance matrix $\left[M_{p h}\right]$ has the structure (4) and contains the mutual inductance of all the machine phases with each single strand.

$$
M_{p h}=\left[\begin{array}{ccc}
M_{1 \_p h 1} & \cdots & M_{1 \_p h x} \\
\vdots & \ddots & \vdots \\
M_{n \_p h 1} & \cdots & M_{n \_p h x}
\end{array}\right]
$$

Thereby the proposed methodology comprises the following main steps highlighted below and illustrated in Fig. 3:

- Inductance matrix evaluation: calculation of self and mutual inductances for all strands of stranded coil as well as between stranded and bulk coils by using subdomain model (SDM)

- Back EMF evaluation: calculation of bEMFs waveforms induced in each strand for one electrical period by using SDM model

- Solution of ODE system (1) - (2) for an equivalent electrical circuit to define the current through each strand.

- AC loss estimation in strands

In the next sections of the paper each of the main steps above will be described in detail. 


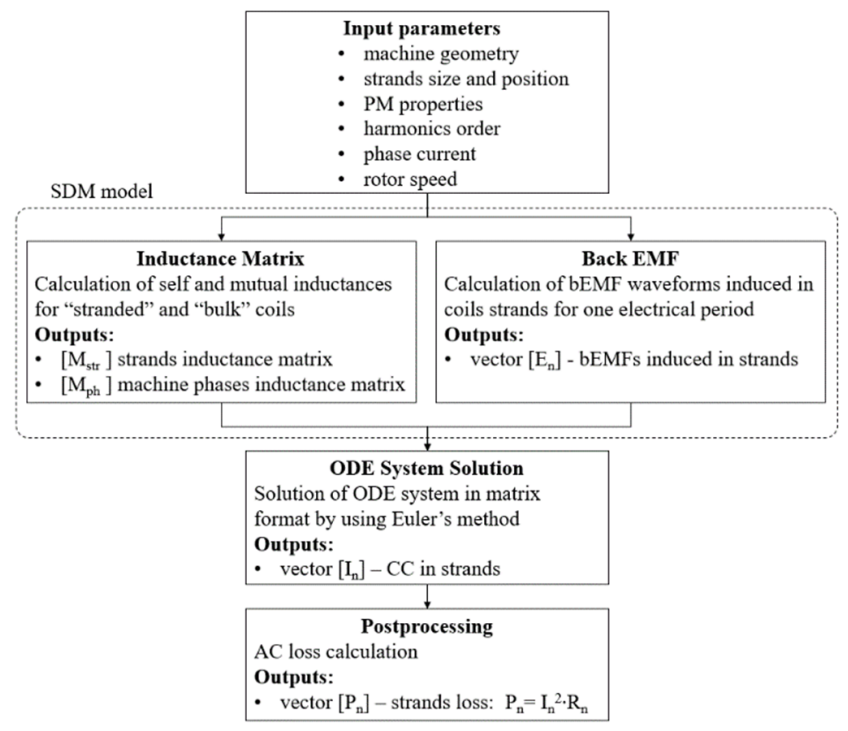

Fig. 3 The sequence of the proposed methodology for circulating current calculation

\section{INDUCTANCE MATRIX}

The inductance matrix can be calculated by using SDM technique. Since the model is linear the PMs can be removed from consideration when the induction matrix have been calculated. When the PMs are «switched off» an arbitrary current can be injected into the source conductors and then the linked flux in all other conductors (probe conductors) can be calculated. Each strand in a turn includes a pair of conductors with «in» and «out» current direction as illustrated in Fig. 4. Once the linked flux in the probe coil is calculated the appropriate self or mutual inductance can be defined via (5).

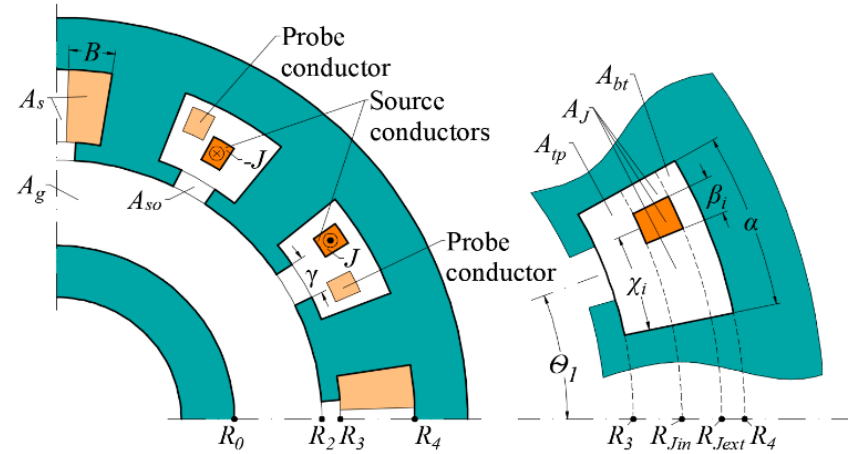

Fig. 4 SDM model geometry for inductance matrix calculation

$$
L=\frac{\Phi}{I}
$$

Where $\Phi$ is the flux linked with a probe conductor and $I$ is an arbitrary current through the pair of source conductors. To define the flux $\Phi$ the magnetic field distribution in each slot with stranded coil needs to be evaluated by solving Maxwell's equations (6) - (7) in all subdomains of machine.

$$
\begin{aligned}
& \left\{\begin{array}{l}
\nabla \cdot B=0 \\
\nabla \times H=0
\end{array}-\mathrm{SDM}\right. \text { without current } \\
& \left\{\begin{array}{l}
\nabla \cdot B=0 \\
\nabla \times H=J
\end{array}-\right.\text { SDM with current }
\end{aligned}
$$

The equations $(6)-(7)$ can be solved by introducing vector magnetic potential (8) which will lead to Laplace's (9) and Poisson's (10) equations.

$$
\begin{gathered}
B=\nabla \times A \\
\Delta A=0-\mathrm{SDM} \text { without current } \\
\Delta A=-\mu_{0} J-\mathrm{SDM} \text { with current }
\end{gathered}
$$

\begin{tabular}{|c|c|c|c|}
\hline SDM Region & Equation & Range of Region & $\begin{array}{c}\text { Number of } \\
\text { Regions }\end{array}$ \\
\hline Air gap & $A_{g}=\sum\left(A_{q} r^{-q}+B_{q} r^{q}\right) \cos (q \theta)+\left(C_{q} r^{-q}+D_{q} r^{q}\right) \sin (q \theta), q=1,2 .$. & $\begin{array}{l}r \in\left[R_{0} ; R_{2}\right] \\
\theta \in[0 ; 2 \pi]\end{array}$ & 1 \\
\hline Slot opening & $A_{s o}=A_{0 s o}+B_{0 s o} \ln r+\sum\left(A_{k} r^{-\varepsilon}+B_{k} r^{\varepsilon}\right) \cos \left[\varepsilon\left(\theta+\frac{\gamma}{2}-\theta_{1}\right)\right], \varepsilon=\frac{k \pi}{\gamma}, k=1,2$ & $\begin{array}{l}r \in\left[R_{2} ; R_{3}\right] \\
\theta \in\left[\theta_{1}-\frac{\gamma}{2} ; \theta_{1}+\frac{\gamma}{2}\right]\end{array}$ & $Z$ \\
\hline $\begin{array}{l}\text { Slot - bulk } \\
\text { coil }\end{array}$ & $\begin{array}{l}A_{s}=A_{0 s}+B_{0 s} \ln r+\frac{\delta_{0} r^{2}}{4}+\sum\left(A_{m} r^{-\omega}+B_{m} r^{\omega}+\frac{\delta_{m} r^{2}}{4-\omega^{2}}\right) \cos \left[\omega\left(\theta+\frac{\alpha}{2}-\theta_{1}\right)\right], m \neq \frac{2 \alpha}{\pi} \\
A_{s}=A_{0 s}+B_{0 s} \ln r+\frac{\delta_{0} r^{2}}{4}+\sum\left(A_{n} r^{-2}+B_{m} r^{2}+\frac{\delta_{n} r^{2}}{4}\left(\frac{2 \ln r-1}{2}\right)\right) \cos \left[\omega\left(\theta+\frac{\alpha}{2}-\theta_{1}\right)\right], m=\frac{2 \alpha}{\pi} \\
\text { where } \omega=\frac{m \pi}{\alpha}, \delta_{n}=-\mu_{0} J_{m}, \delta_{0}=-\mu_{0} J_{0}, m=1,2\end{array}$ & $\begin{array}{l}r \in\left[R_{3} ; R_{4}\right] \\
\theta \in\left[\theta_{1}-\frac{\alpha}{2} ; \theta_{1}+\frac{\alpha}{2}\right]\end{array}$ & $Z-Z_{\text {str }}$ \\
\hline $\begin{array}{l}\text { Slot top - } \\
\text { stranded coil }\end{array}$ & $A_{t p}=A_{0 t p}+B_{0 t p} \ln r+\sum\left(A_{t p_{-} m} r^{-\omega}+B_{t p_{-} m} r^{\omega}\right) \cos \left[\omega\left(\theta+\frac{\alpha}{2}-\theta_{1}\right)\right]$ & $\begin{array}{l}r \in\left[R_{3} ; R_{J i n}\right] \\
\theta \in\left[\theta_{1}-\frac{\alpha}{2} ; \theta_{1}+\frac{\alpha}{2}\right]\end{array}$ & $Z_{\text {str }}$ \\
\hline $\begin{array}{l}\text { Conductor - } \\
\text { stranded coil }\end{array}$ & $\begin{array}{l}A_{J}=A_{0 J}+B_{0 J} \ln r+\frac{\delta_{0} r^{2}}{4}+\sum\left(A_{J_{-} m} r^{-\omega}+B_{J_{-}} r^{\omega}+\frac{\delta_{n} r^{2}}{4-\omega^{2}}\right) \cos \left[\omega\left(\theta+\frac{\alpha}{2}-\theta_{1}\right)\right], m \neq \frac{2 \alpha}{\pi} \\
A_{J}=A_{0 J}+B_{0 J} \ln r+\frac{\delta_{0} r^{2}}{4}+\sum\left(A_{J_{m}} r^{-2}+B_{J_{m}} r^{2}+\frac{\delta_{n} r^{2}}{4}\left(\frac{2 \ln r-1}{2}\right)\right) \cos \left[\omega\left(\theta+\frac{\alpha}{2}-\theta_{1}\right)\right] \\
m=\frac{2 \alpha}{\pi} \\
\text { where } \omega=\frac{m \pi}{\alpha}, \delta_{n}=-\mu_{0} J_{m}, \delta_{0}=-\mu_{0} J_{0}, m=1,2 .\end{array}$ & $\begin{array}{l}r \in\left[R_{\text {Jin }} ; R_{\text {Jext }}\right] \\
\theta \in\left[\theta_{1}-\frac{\alpha}{2} ; \theta_{1}+\frac{\alpha}{2}\right]\end{array}$ & $Z_{\text {str }}$ \\
\hline $\begin{array}{l}\text { Slot bottom - } \\
\text { stranded coil }\end{array}$ & $A_{b t}=A_{0 b t}+B_{0 b t} \ln r+\sum\left(A_{b t_{-} m} r^{-\omega}+B_{b t_{-} m} r^{\omega}\right) \cos \left[\omega\left(\theta+\frac{\alpha}{2}-\theta_{1}\right)\right]$ & $\begin{array}{l}r \in\left[R_{\text {Jext }} ; R_{4}\right] \\
\theta \in\left[\theta_{1}-\frac{\alpha}{2} ; \theta_{1}+\frac{\alpha}{2}\right]\end{array}$ & $Z_{\text {str }}$ \\
\hline
\end{tabular}

TABLE 1

EOUATIONS OF SDM MODEL 
The detailed solution of (9) and (10) is well known and was given in [13]. Table 1 contains the description of SDM regions and the appropriate equations for vector magnetic potential. The equations (11) - (16) contain unknown coefficients that can be found by applying the boundary conditions described in Table 2.

Fourier decomposition of conductor current density for the defined angular position $\chi$ in the slot and the angular dimension $\beta$ Fig. 4 for equation (15) can be expressed as (17).

$$
J=J_{0}+\sum_{m=1,2 . .} J_{m}
$$

Where $J_{0}$ the DC part (18) and $J_{m}$ is the AC part (19) of Fourier series.

$$
\begin{gathered}
J_{0}=\frac{J \beta}{\alpha} \\
J_{m}=\frac{4}{m \pi} J \sin \left(\frac{m \pi \beta}{2 \alpha}\right) \cos \left(\frac{m \pi \chi}{\alpha}\right) \cos \left[\omega\left(\theta+\frac{\alpha}{2}-\theta_{1}\right)\right]
\end{gathered}
$$

For the bulk coil with the angular dimension $B$ the decomposition of current density in the slot will look as (20) for the coils located on the right side of the slot Fig. 4 and as (21) for the left side bulk coils.

$$
\begin{gathered}
J_{m}=\frac{4}{n \pi} J \sin \left(\frac{m \pi \mathrm{B}}{2 \alpha}\right) \cos \left(\frac{m \pi \mathrm{B}}{2 \alpha}\right) \cos \left[\omega\left(\theta+\frac{\alpha}{2}-\theta_{1}\right)\right] \\
J_{m}=\frac{4}{n \pi} J \sin \left(\frac{m \pi \mathrm{B}}{2 \alpha}\right) \cos \left(\frac{m \pi(\alpha-\mathrm{B} / 2)}{\alpha}\right) \cos \left[\omega\left(\theta+\frac{\alpha}{2}-\theta_{1}\right)\right](21) \\
\text { TABLE } 2
\end{gathered}
$$

BOUNDARY CONDITIONS OF SDM MODEL

$\left.\begin{array}{ll}\hline \hline \multicolumn{1}{c}{\text { Boundary }} & \multicolumn{1}{c}{\text { Boundary Condition }} \\ \hline r=R_{0} & \frac{\partial A_{g}}{\partial r}=0, \forall \theta \in[0 ; 2 \pi] \\ r=R_{2} & \frac{\partial A_{g}}{\partial r}=\left\{\begin{array}{l}\left.\frac{\partial A_{s o}}{\partial r}\right|_{r=R_{2}} \forall \theta \in\left[\theta_{1}-\frac{\gamma}{2} ; \theta_{1}+\frac{\gamma}{2}\right] \\ 0 \text { elsewhere }\end{array}\right. \\ & A_{s o}=A_{g}, \forall \theta \in\left[\theta_{1}-\frac{\gamma}{2} ; \theta_{1}+\frac{\gamma}{2}\right]\end{array}\right\}$

The development of the boundary conditions (BCs) (22) (34) will lead to the system of $2 Z\left(2+m_{\max }+k\right)+$ $4 Z_{\text {str }}\left(1+m_{\max }\right)+4 q$ linear equations which can be solved to define the unknown coefficients of (11) - (16).

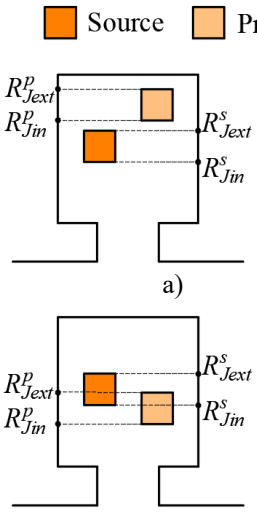

d)

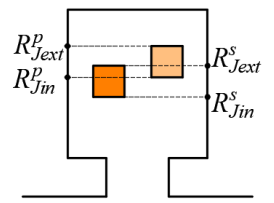

b)

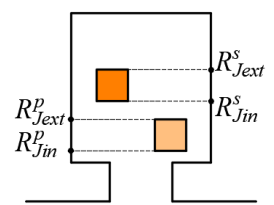

e)

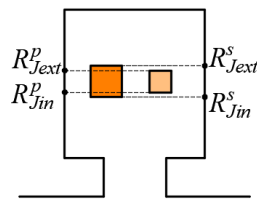

c)

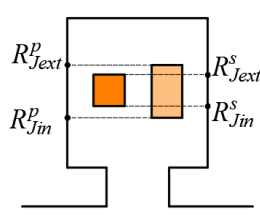

f)
Fig. 5 To the flux linkage evaluation

Once the function of vector potential in the slot is defined the flux linked with each single conductor can be calculated as an average value of vector potential within the conductor area. There are 6 different cases of probe conductor location with respect to the source conductor that needs to be considered Fig. 5. The probe conductor can be located in $A_{b t}$ region - case (a), partially in $A_{b t}$ and $A_{J}$ region - case (b), totally in $A_{J}$ region case (c) (in general, the probe and source conductors can differ in size), between and $A_{J}$ and $A_{t p}$ region - case (d), in $A_{t p}$ region - case (e) and in all three regions - case f.

Variations of flux linkage calculation with change in relative location of the probe conductor are summarized in Table 3. In

\begin{tabular}{|c|c|c|}
\hline Case & $\begin{array}{c}\text { Logical } \\
\text { Condition }\end{array}$ & Expression for Flux Linkage Evaluation \\
\hline $\mathrm{a}$ & $R_{\text {Jin }}^{p} \geq R_{\text {Jext }}^{S}$ & $\begin{array}{l}\Phi=\frac{l}{S_{\text {cond }}} \int_{R_{\text {Jin }}^{p}}^{R_{\text {Jext }}^{p}} \int_{\chi-\frac{\beta}{2}}^{\chi+\frac{\beta}{2}} A_{b t} r d r d \theta \\
l \text { is an active length, } S_{\text {cond }} \text { is a conductor are }\end{array}$ \\
\hline $\mathrm{b}$ & $\begin{array}{l}R_{\text {Jext }}^{p}>R_{\text {Jext }}^{s} \cup \\
R_{\text {Jin }}^{p}<R_{\text {Jext }}^{s} \cup \\
R_{\text {Jin }}^{p}>R_{\text {Jin }}^{S}\end{array}$ & $\begin{array}{l}\Phi=\frac{l}{S_{1}} \int_{R_{\text {Jin }}^{p}}^{R_{\text {Jext }}^{s}} \int_{\chi-\frac{\beta}{2}}^{\chi+\frac{\beta}{2}} A_{J} r d r d \theta+ \\
\frac{l}{S_{2}} \int_{R_{\text {Jext }}^{s}}^{R_{\text {Jext }}^{p}} \int_{\chi-\frac{\beta}{2}}^{\chi+\frac{\beta}{2}} A_{b t} r d r d \theta \text {, here } S_{1} \text { and } S_{2} \text { are } \\
\text { the areas of the probe conductor belonging to } \\
\text { an appropriate region, }\end{array}$ \\
\hline $\mathrm{c}$ & $\begin{array}{l}R_{\text {Jext }}^{p} \leq R_{\text {Jext }}^{s} \cup \\
R_{\text {Jin }}^{p} \geq R_{\text {Jin }}^{s}\end{array}$ & $\Phi=\frac{l}{S_{\text {cond }}} \int_{R_{J i n}^{p}}^{R_{\text {Jin }}^{p}} \int_{\chi-\frac{\beta}{2}}^{\chi+\frac{\beta}{2}} A_{J} r d r d \theta$ \\
\hline $\mathrm{d}$ & $\begin{array}{l}R_{\text {Jext }}^{p}>R_{\text {Jin }}^{s} \cup \\
R_{\text {Jin }}^{p}<R_{\text {Jin }}^{s} \cup \\
R_{\text {Jext }}^{p}<R_{\text {Jext }}^{s}\end{array}$ & $\begin{array}{l}\Phi=\frac{l}{s_{1}} \int_{R_{J i n}^{S}}^{R_{J i n}^{p}} \int_{\chi-\frac{\beta}{2}}^{\chi+\frac{\beta}{2}} A_{J} r d r d \theta+ \\
\frac{l}{s_{2}} \int_{R_{J i n}^{p}}^{R_{J i n}^{S}} \int_{\chi-\frac{\beta}{2}}^{\chi+\frac{\beta}{2}} A_{t p} r d r d \theta\end{array}$ \\
\hline $\mathrm{e}$ & $R_{\text {Jext }}^{p} \leq R_{\text {Jin }}^{s}$ & $\Phi=\frac{l}{S_{\text {cond }}} \int_{R_{\text {Jin }}^{p}}^{R_{\text {jext }}^{p}} \int_{\chi-\frac{\beta}{2}}^{\chi+\frac{\beta}{2}} A_{t p} r d r d \theta$ \\
\hline $\mathrm{f}$ & $\begin{array}{l}R_{\text {Jext }}^{p}>R_{\text {Jext }}^{s} \cup \\
R_{\text {Jin }}^{p}<R_{\text {Jin }}^{s}\end{array}$ & $\begin{array}{l}\Phi=\frac{l}{s_{1}} \int_{R_{J i n}^{J}}^{R_{J}^{s}} \int_{\chi-\frac{\beta}{2}}^{\chi+\frac{\beta}{2}} A_{J} r d r d \theta+ \\
\frac{l}{s_{2}} \int_{R_{\text {Jext }}^{S}}^{R_{\text {Jext }}^{p}} \int_{\chi-\frac{\beta}{2}}^{\chi+\frac{\beta}{2}} A_{b t} r d r d \theta+ \\
\frac{l}{s_{3}} \int_{R_{\text {Jin }}^{p}}^{R_{J i n}^{S}} \int_{\chi-\frac{\beta}{2}}^{\chi+\frac{\beta}{2}} A_{t p} r d r d \theta\end{array}$ \\
\hline
\end{tabular}
the cases where the probe conductor is located between several regions the flux linkage is calculated as a sum flux linkages belonging to the covered area of corresponding region - the cases (b), (d), and (f).

TABLE 3 
The self-inductance of source conductor and mutual inductance between machine phases and conductors is calculated by (41).

$$
\Phi=\frac{l}{S_{\text {cond }}} \int_{R_{\text {Jin }}^{S}}^{R_{\text {Jext }}^{S}} \int_{\chi-\frac{\beta}{2}}^{\chi+\frac{\beta}{2}} A r d r d \theta
$$

Here $A$ needs to be substituted with $A_{J}$ for the self-inductance calculation and with $A_{s}$ for the mutual inductance.

If the self and mutual inductances of all the conductors are defined then the strand self and mutual inductance can be calculated via summation of conductors connected in series and of which the strand consists. For instance the formula for selfinductance of the $1^{\text {st }}$ strand Fig. 2 is (42), for the mutual inductance of the first and $\mathrm{n}^{\text {th }}$ strand is (43) and for the mutual inductance of the $1^{\text {st }}$ strand and $\mathrm{x}^{\text {th }}$ phase is (44).

$$
\begin{aligned}
& L_{S 1}=\sum_{i=1 . . j} L_{C i} \\
& M_{1 \_n}=\sum_{i=1 . . j} M_{C i \_n} \\
& M_{1 \_p h x}=\sum_{i=1 . . j} M_{C i \_p h x} \\
& \text { V. BACK EMF }
\end{aligned}
$$

To calculate the bEMF in each strand the equation (13) needs to be written in a form (45) since the current density in the slots is zero.

$$
\begin{gathered}
A_{s}=A_{0 s}+B_{0 s} \ln r+ \\
\sum\left(A_{m} r^{-\omega}+B_{m} r^{\omega}\right) \cos \left[\omega\left(\theta+\frac{\alpha}{2}-\theta_{1}\right)\right]
\end{gathered}
$$

The range of the air gap region $A_{g}$ should be changed to $r \in$ $\left[R_{1} ; R_{2}\right]$ and the SDM region $A_{P M}$ related to PM needs to be introduced (46) Fig. 6. An ideal segmentation of Halbach array have been assumed for PMs region: in each segment of PM the DOM is constant in radial and tangential direction. The Fourier decomposition of the PM magnetization function is given in [14].

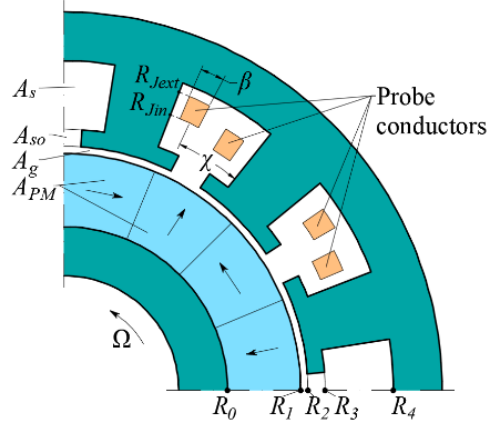

Fig. 6 SDM model geometry for bEMF calculation

The equation (46) describes the distribution magnetic vector potential in PM region.

$$
\Delta A=\mu_{0} \nabla \times M
$$

The solution of (46) was described in [13], [15] and can be written as (47) - (48).

$$
\begin{gathered}
A_{P M}=\sum_{q=2}^{\infty}\left(A_{q}^{P M} r^{-q}+B_{q}^{P M} r^{q}+\frac{\delta_{1}}{1-q^{2}} r\right) \cos [q(\theta+\Delta)]+ \\
\left(C_{q}^{P M} r^{-q}+D_{q}^{P M} r^{q}+\frac{\delta_{2}}{1-q^{2}} r\right) \sin [q(\theta+\Delta)], \text { for } q>1(47) \\
A_{P M}=\left[A_{q}^{P M}{ }_{q} r^{-q}+B_{q}^{P M} r^{q}+\frac{\delta_{1} r\left(\ln r-\frac{1}{2}\right)}{2}\right] \cos (\theta+\Delta)+ \\
{\left[C_{q}^{P M} r^{-1}+D_{q}^{P M} r+\frac{\delta_{2} r\left(\ln r-\frac{1}{2}\right)}{2}\right] \sin (\theta+\Delta), \text { for } q=1}
\end{gathered}
$$

Where $\Delta=\frac{\pi}{2 p s}-\Delta_{1}, \Delta_{1}$ is the rotor position, $s$ is the number of segments per pole pitch, $q=1,2 . . \infty$ - harmonic order, $\delta_{1}$ and $\delta_{2}$ are (49) and (50) respectively.

$$
\begin{aligned}
& \delta_{1}=\mu_{0} q M_{r s}-\mu_{0} M_{\theta c} \\
& \delta_{2}=-\mu_{0} q M_{r c}-\mu_{0} M_{\theta s}
\end{aligned}
$$

Where $M_{r s}, M_{r c}, M_{\theta s}, M_{\theta c}$ are the expressions corresponding to $\sin$ and cos parts of the magnetization functions $M_{r}$ and $M_{\theta}$ of rotor - given in the Appendix of [14].

The BC at the boundary $R_{0}$ and $R_{1}$ are (51) - (53) Fig. 6.

$$
\begin{gathered}
\left.\frac{\partial A_{P M}}{\partial r}\right|_{r=R_{0}}=\left\{\begin{array}{c}
0, \quad \text { for radial component } \\
-\mu_{0} M_{\theta}, \text { for tangential component }
\end{array}\right. \\
A_{P M}=A_{g}, \text { at } r=R_{1} \\
\frac{\partial A_{g}}{\partial r}=\frac{\partial A_{P M}}{\partial r}, \text { at } r=R_{1}
\end{gathered}
$$

The BCs (51) - (53) will lead to the linear equations which needs to be solved together with the ones from the BCs (23) (27) to define the vector potential in the slot $A_{s}$.

Once the function $A_{s}$ is defined the flux linked with each conductor can be calculated by the formula (41) for a particular rotor position. This procedure has to be repeated for all rotor positions related to one electrical period with the time step $\Delta t$. Then the bEMF in the $\mathrm{m}^{\text {th }}$ conductors can be calculated as a derivative of the flux linkage of that conductor over time (54).

$$
E_{C m}=-\frac{\partial \Phi_{C m}}{\partial t}
$$

The bEMF of the strand is the sum of all the bEMFs of the conductors included in the strand. For instance (55) is the expression for the bEMF calculation of the $1^{\text {st }}$ strand.

$$
E_{1}=\sum_{i=1 . . m} E_{C i}
$$

\section{ODE SYSTEM SOLUTION}

The system of ordinary differential equations (ODE) (1) - (2) can be solved by using Euler's method. All the derivatives in (1) have been replaced by the finite difference approximation (56).

$$
\frac{d y}{d t} \approx \frac{y_{i}-y_{i-1}}{\Delta t}
$$

Where $\Delta t$ is the time-step; $y_{i}$ is the value of the function at the current step and $y_{i-1}$ is the value of the function at the previous step. By introducing (56) and after some treatment the ODE system (1) - (2) can be written in a matrix format (57). 


$$
\left[\begin{array}{cccc}
\frac{L_{1}}{\Delta t} & \cdots & \frac{M_{1 \_n}}{\Delta t} & R_{1} \\
\vdots & \vdots & \vdots & \vdots \\
\frac{M_{n \_1}}{\Delta t} & \cdots & \frac{M_{n \_n}}{\Delta t} & R_{1} \\
1 & \cdots & 1 & 0
\end{array}\right]\left[\begin{array}{c}
I_{1}^{i} \\
I_{2}^{i} \\
\vdots \\
I_{n}^{i}
\end{array}\right]=\left[\begin{array}{c}
U^{i}-E_{1}^{i}+L_{S 1} \frac{I_{1}^{i-1}}{\Delta t}+\ldots+M_{1_{n}} \frac{I_{n}^{i-1}}{\Delta t}-M_{1_{p h 1}} \frac{I_{p h_{1}}^{i}-I_{p h_{1}}^{i-1}}{\Delta t}-\cdots-M_{1_{p h x}} \frac{I_{p h_{x}}^{i}-I_{p h_{x}}^{i-1}}{\Delta t} \\
\vdots \\
U^{i}-E_{2}^{i}+M_{S 2_{-} 1} \frac{I_{1}^{i-1}}{\Delta t}+\ldots+M_{2_{n}} \frac{I_{n}^{i-1}}{\Delta t}-M_{2 p h 1} \frac{I_{p h_{1}-I_{p h_{1}}^{i}}^{i-1}}{\Delta t}-\cdots-M_{2 p h x} \frac{I_{p h_{x}-I_{p h_{x}}^{i-1}}^{i t}}{\Delta t}
\end{array}\right]
$$

The vector of initial conditions for $I_{1}^{0} . . I_{n}^{0}$ needs to be specified. It can be set to zero if the initial current $I^{0}=0$. After that the system (57) can be solved by standard methods for solving linear systems of algebraic equations - as the result the currents $I_{1} . . I_{n}$ as well as the voltage $U$ can be found.

\section{COMPARISON WITH FEM}

The application of the proposed methodology for evaluation of circulating current loss for a machine with a 3-phase concentrated winding with 15 pole pairs and 36 slots has been presented in this section. The parameters of the machine are listed in Table 4. The aim of this section is to demonstrate the significant effects of $\mathrm{CC}$ losses in machines with high fundamental frequency as well as validation of the proposed model against an FEM based model. Linear (no saturation) and nonlinear material properties were considered for validation of the computational method. It should be noted in advance that the machine described here was prototyped with litz wire to suppress the effect of $\mathrm{CC}$ currents.

TABLE 4

PARAMETERS OF THE MOTOR FOR COMPARISON WITH

\begin{tabular}{|c|c|c|}
\hline Parameter & Description & Value \\
\hline$M$ & Magnetization & $923 \mathrm{kA} / \mathrm{m}$ \\
\hline$p$ & Pole pairs & 15 \\
\hline$s$ & Number of segments per pole pitch & 2 \\
\hline$Z$ & Number of slots & 36 \\
\hline$\beta$ & Coil span & $0.273^{\circ}$ \\
\hline$I$ & Phase current & 523 Apeak \\
\hline \multirow[t]{4}{*}{$f$} & Fundamental frequency & $750 \mathrm{~Hz}$ \\
\hline & Nominal speed & $3000 \mathrm{rpm}$ \\
\hline & Number of phases & 3 \\
\hline & Diameter of equivalent round wire & $1 \mathrm{~mm}$ \\
\hline$q_{\max }$ & $\begin{array}{l}\text { Maximum harmonic order in PM and } \\
\text { air gap subdomains }\end{array}$ & 100 \\
\hline$n_{\max }$ & $\begin{array}{l}\text { Maximum harmonic order in slot } \\
\text { subdomain }\end{array}$ & 10 \\
\hline \multirow[t]{5}{*}{$k_{\max }$} & $\begin{array}{l}\text { Maximum harmonic order in inner } \\
\text { slot opening subdomain }\end{array}$ & 10 \\
\hline & Winding configuration & concentrated \\
\hline & Winding temperature & $200^{\circ} \mathrm{C}$ \\
\hline & Core material & Vacoflux 48 \\
\hline & Boundary conditions/periodicity angle & Odd periodic $\left(60^{\circ}\right)$ \\
\hline
\end{tabular}

For this example the uniform strands arrangement was chosen Fig. 7. The cross-section of all the conductors in the slot is kept the same by normalizing the area of the conductors to the round wire with equivalent area. The strands are placed horizontally within a bundle: 5 stands in a row, 6 layers in a bundle. The order of the strands is highlighted in red arrows in Fig. 7. The coil was fed by sinusoidal current source with an amplitude of $523 \mathrm{~A}$ and the frequency of $750 \mathrm{~Hz}$. FEM results are presented in Fig. 7 which shows the uneven distribution of current density $\left(\mathrm{A} / \mathrm{m}^{2}\right)$ between the strands.

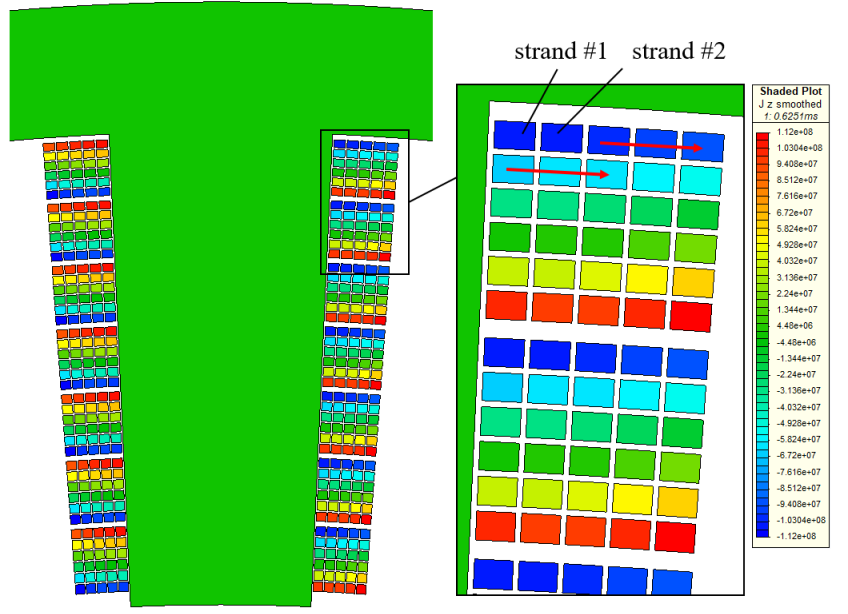

Fig. 7 Instantaneous current density $\left[\mathrm{A} / \mathrm{m}^{2}\right]$ distribution in the coil - FEM-linear results

The comparison of the current waveforms of specific strands derived from FEM-linear and analytical modelling respectively are given in Fig. 8 (left). The circulating current can be observed even without load as in Fig. 8 (right). This shows the comparison of the current through the strands when the net phase current is zero (machine is open circuited). Once the current through each strand of the coil is defined, the Ohmic AC loss of each strand can be easily estimated as $P=I_{n}^{2} \cdot R_{n}$ where $I_{n}$ is the current and $R_{n}$ is the resistance of $\mathrm{n}^{\text {th }}$ strand. Fig. 9 shows the comparison of AC loss for each strand at full load and no load condition with FEM-linear and nonlinear modelling. The AC losses without load are significantly lower but still unevenly distributed among the strands as it shown in Fig. 9 (bottom plot). The comparison is given for the first harmonic of magnetic field in the considered subdomains (grey label) as well as for high order harmonics (blue label) which gives better accuracy.

Figure 10 demonstrates the attained total slot $\mathrm{AC}$ losses from the analytical and FEM models described above against results form a nonlinear FEM simulation. This shows acceptable agreement for the intended use of the proposed modelling technique. For the machine example considered in this section the total AC losses in the slot are about $1630 \mathrm{~W}$ for the case when the saturation effects are accounted for (FEM nonlinear), $1860 \mathrm{~W}$ when the saturation effects are neglected (FEM linear). The proposed analytical model gives the value of $1840 \mathrm{~W}$ for the total AC loss in the slot which overpredicts the result by $12.9 \%$ against nonlinear FEM. The analytical and FEM linear models are within $1.1 \%$ of each other. 

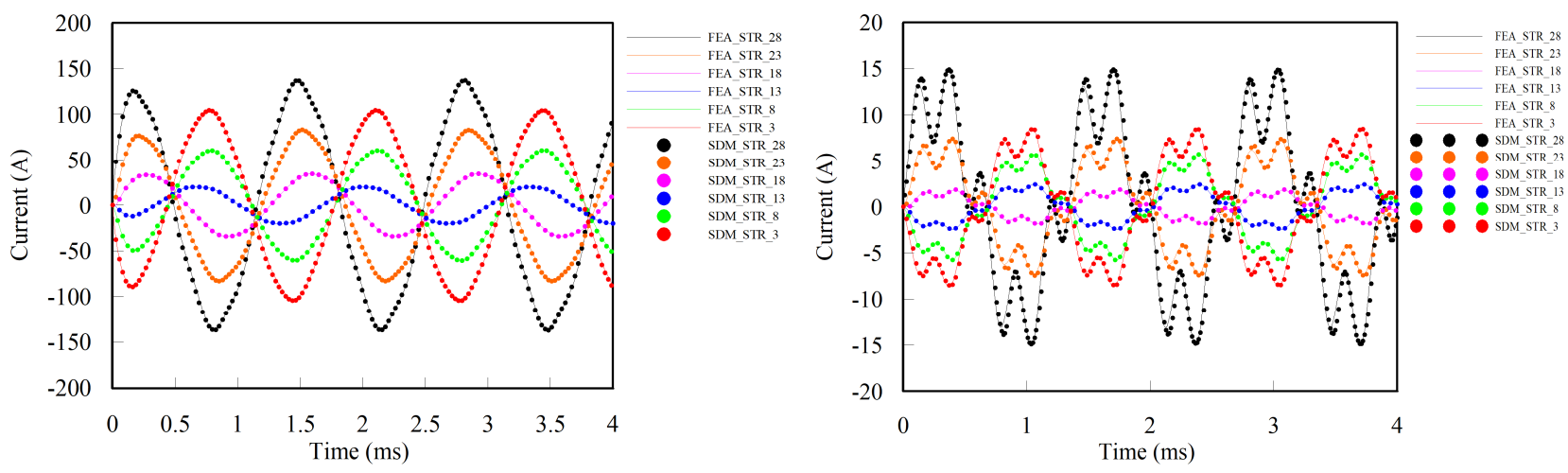

Fig. 8 Uneven current distribution between the parallel strands - comparison of analytical (SDM) and FEM-linear results: (left) - at full load, (right) - no load
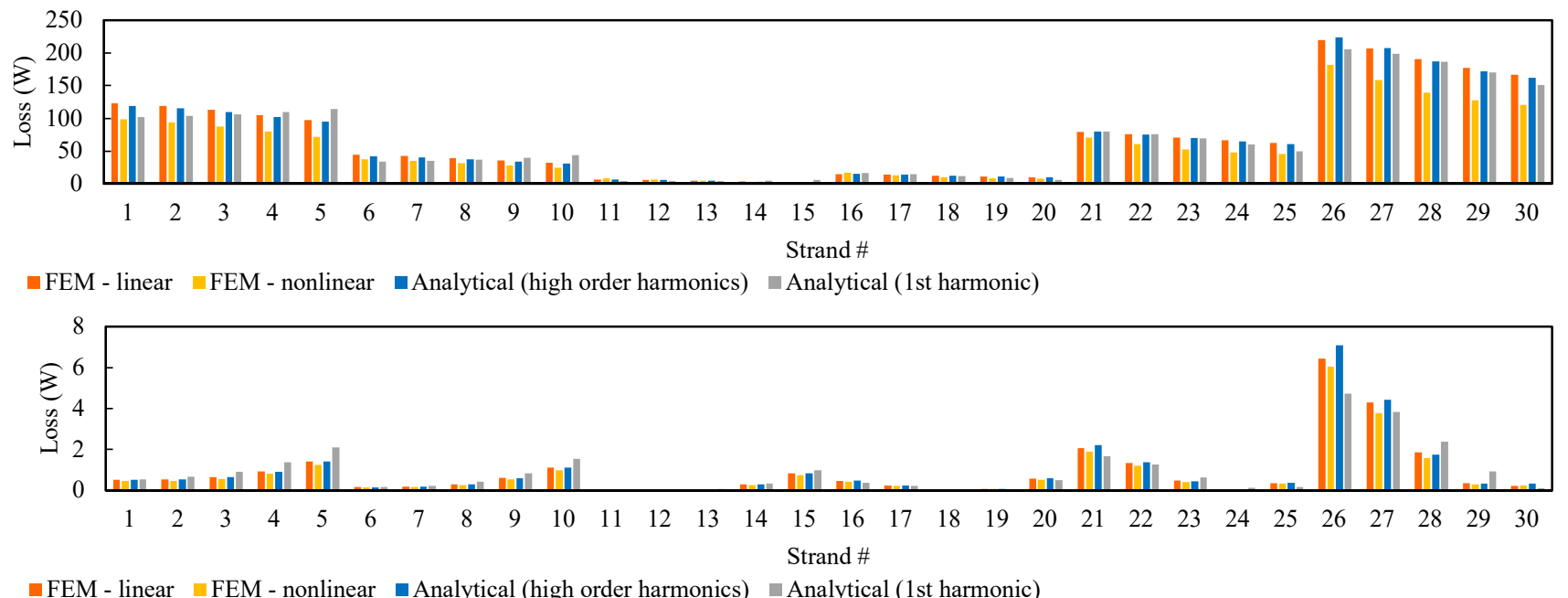

—FEM - linear $\square$ FEM - nonlinear $\square$ Analytical (high order harmonics) $\square$ Analytical (1st harmonic)

Fig. 9 Uneven distribution of AC loss in the strands - comparison FEM with analytical model (upper figure) - at full load (bottom figure) - no load

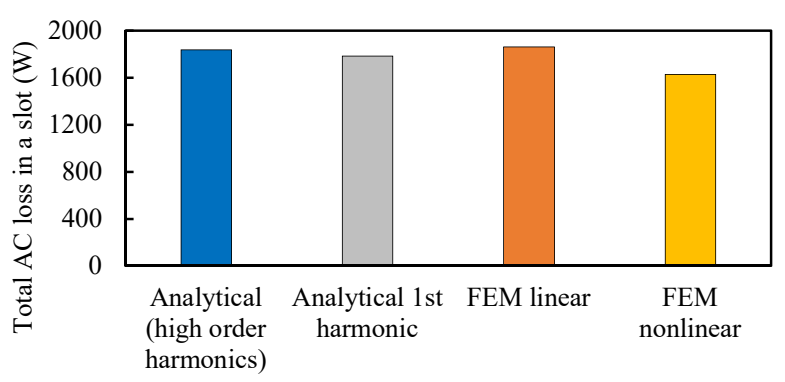

Fig. 10 Comparison of total AC losses at full load in a slot

This example is selected to demonstrate the proposed methodology and the potential impact of CC losses if an appropriate mitigation strategy is not considered. For presented case study the use of bunches with parallel round wire leads to a very high current density and copper losses Fig. 7, Fig. 9.

High order magnetic field harmonics generated as a result of the airgap permeance variation and current harmonics can have an impact on the estimation of CC losses. To demonstrate this impact on the $\mathrm{CC}$ waveform, the CCs for the first harmonic of vector potential in all considered subdomains were calculated analytically and then superimposed with the ones where the high order harmonics of magnetic fields were considered as shown in Fig. 11. It is clearly seen that there is a difference that can be attributed to this. These differences can vary depending on the conductor location as shown in Fig.9. Fig. 12 shows the estimated error between FEM-linear and analytical model in case of considering only the fundamental harmonic of magnetic field in the subdomains and in case of considering high order harmonics. Without consideration of high order harmonics the error varies in the range from $2 \%$ to $10.5 \%$ for the presented strands for on-load condition while in case of taking into account the high order harmonics the error range drops to $1 \%$ $7.8 \%$ as shown in Fig. 12.

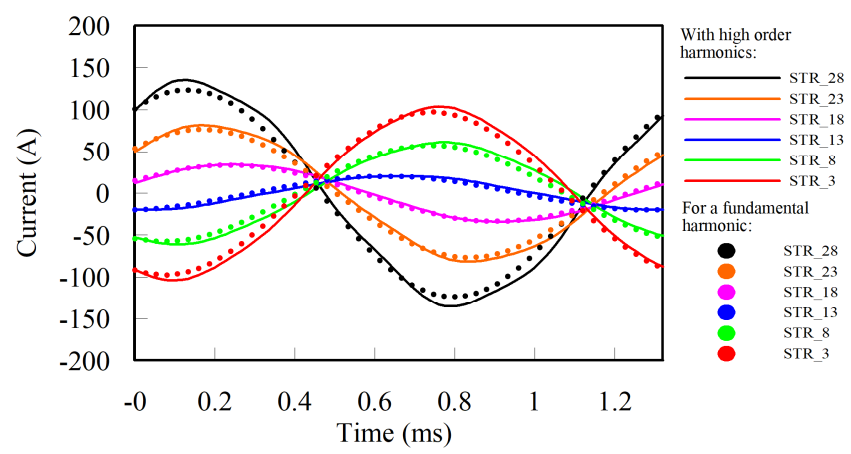

Fig. 11 An impact of high order harmonics of magnetic field on the circulating current waveform at on load condition (analytical modelling) 


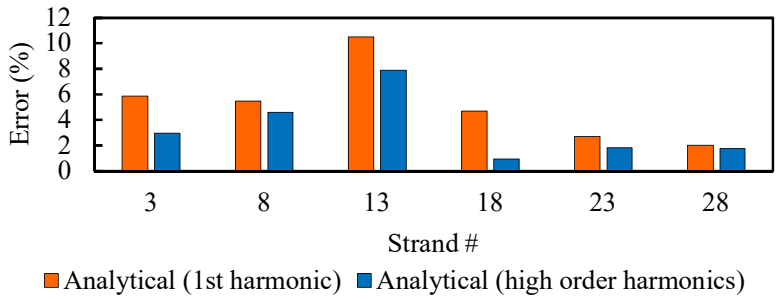

Fig. 12 Strand to strand error estimation for the proposed model for the case of engagement high order field harmonics of magnetic field and only the 1st harmonic (the errors were estimated with respect to FEM - linear model)

Fig. 13 shows the total harmonic distortion (THD) for the circulating currents presented in Fig. 8 for full load and no load cases. The circulating current THD varies from $2 \%$ to $3 \%$ for on load condition and from $21 \%$ to $39 \%$ for no load condition for the presented strands.

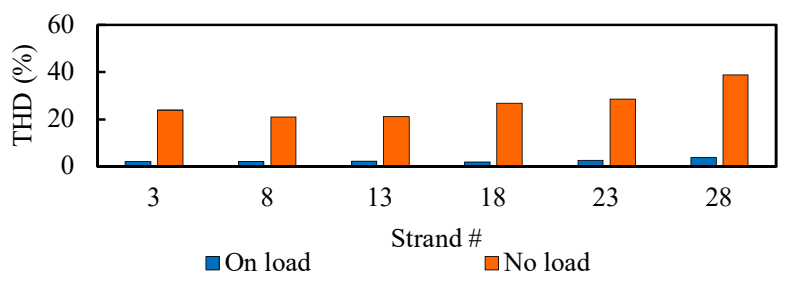

Fig. 13 The circulating current THD for no-load and on load case

\section{EXPERIMENTAL VALIDATION}

The experimental validation of the model was performed for a stator section (motorette) of the machine as presented Fig. 14. The geometry, materials and winding of the motorette were selected to represent a generic motor case and for convenience of the experimental setup. A semi-closed slot design to engage all the subdomains considered in the model was opted for. Given the lack of a rotor, in the experimental validation the influence of rotor (bEMF) is clearly not considered and only the armature effects are. This however can be justified as all the critical parameters of the proposed model are validated including the inductance matrix, SDM and ODE model blocks in Fig. 3. The block related to the bEMF was validated in the previous section via comparison with FEM. It should be also noted that the impact of the rotor on AC loss is not significant as it was shown in [16] and [17].

The core of the motorette is made of high grade silicon steel 10JNHF600 with the lamination thickness of $0.1 \mathrm{~mm}$ to suppress as much as possible the hysteresis and eddy-current effects in the core and minimize their impact on the results. The core has two semi-closed slots with two plastic blocks inside. Each plastic block has a set of staggered holes that hold the wire in a predefined place in the slot as shown in Fig. 14. The coil comprises 4 parallel strands with 5 turns in each strand. The strands arrangement is highlighted in different grey shades in Fig. 14 b.

The flowchart of the experiment and the comparison with analytical model is given Fig. 15. The experiment consists of two tests. At the preliminary stage within the scope of Test 1 the inductance matrix of all the strands was measured by LCRanalyzer and an impedance analyzer. The purpose of the Test 1 is to define in conjunction with 2D FEM analysis the additional inductance matrix for the end-winding of the coil which is not calculated analytically in the model.

The Test 1 procedure is the following: at the first step the self-inductance of each strand was measured individually to fill in the main diagonal on the inductance matrix. At the next step an inductance of two strands connected in series was measured. In this case the measured inductance is the sum of selfinductances of the strands and double of mutual inductance between those strands connected in series. For instance for the $1^{\text {st }}$ and $2^{\text {nd }}$ strand we have the equation (58)

$$
L_{2 \_s t r \_i n \_s e r i e s}=L_{1}+L_{2}+2 M_{12}
$$

Here $M_{12}$ is the measured mutual inductance between the strand 1 and $2, L_{2}$ str in series is the measured inductance of two strands connected in series, $L_{1}$ and $L_{2}$ is the measured self inductance of the first and the second strand respectively. From the equation (58) a measured mutual inductance can be obtained as (59).

$$
M_{12}=\frac{L_{2 \_s t r \_i n \_s e r i e s}-L_{1}-L_{2}}{2}
$$

It should be mentioned that $\mathrm{M}_{12}=\mathrm{M}_{21}$ so the inductance matrix is symmetrical.

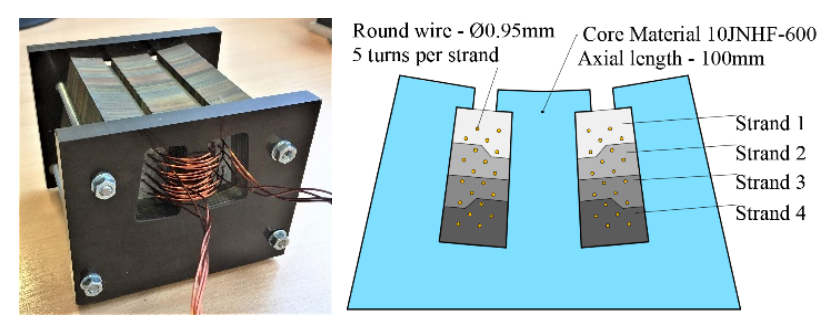

Fig. 14 a) the motorette for experimental validation; b) the motorette description and strands distribution

As the result the end-winding inductance matrix was evaluated as a difference between the measured matrix, which contains both the end-winding and active length self and mutual inductances, and the matrix calculated by 2D FEM which contains the self and mutual inductance for the active length only (Fig. 15). That additional end-winding inductance matrix was added to the main inductance matrix in the analytical model. The comparison of the analytical results with the experiment is given for both cases 2D analytical and 2D analytical with end-winding influence.

The Test 2 (main test) was perform by using a sinusoidal current source at the frequency of $500 \mathrm{~Hz}, 1000 \mathrm{~Hz}$ and $2000 \mathrm{~Hz}$. To avoid the wire resistance increase due to the temperature rise the current density value in the strands was kept reasonably low by supplying the current with the value of 2 Arms. The aforementioned current was supplied into the parallel strands 1-4 and recorded together with the currents through each single strand. The current waveforms were acquired by an oscilloscope - Tektronix MSO 2024 with a bandwidth $200 \mathrm{MHz}$, and a sample rate of $1 \mathrm{GS} / \mathrm{s}$. The used current probe is Fluke i30s with a nominal current range 20 Arms, lowest measured current $50 \mathrm{~mA}$ and useable frequency range $\mathrm{DC}-20 \mathrm{kHz}$. 
End-winding Matrix Evaluation

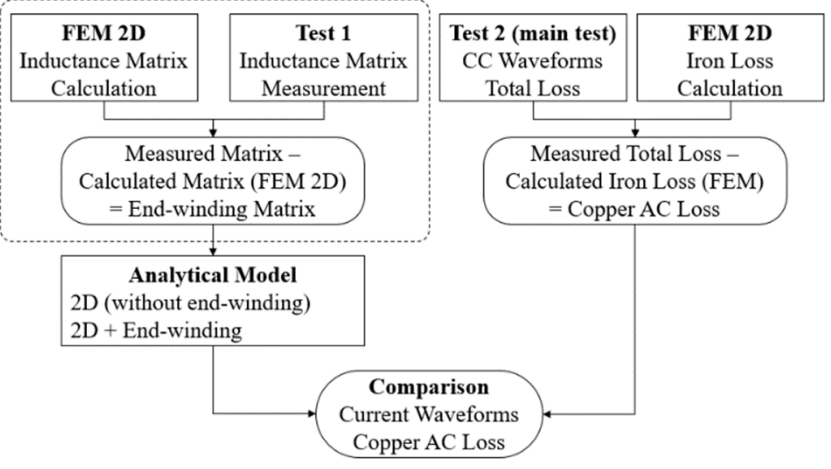

Fig. 15 The experimental validation flowchart

High grade silicon steel 10JNHF600 with $0.1 \mathrm{~mm}$ laminations allows a significant suppression of hysteresis and eddy-current loss in the core. Nevertheless, to take these losses into account the iron core losses have been calculated by FEM and subtracted from the measured total loss as shown in Fig. 15. For instance at $2 \mathrm{~A}(\mathrm{rms})$ and $2 \mathrm{kHz}$ of fundamental frequency the calculated iron losses are $3.2 \mathrm{~mW}$ (according to Steinmetz method for iron loss estimation) which is about $3 \%$ of the losses in the copper.

The result of comparison of the measured current waveforms with the ones predicted by the analytical model at $1 \mathrm{kHz}$ is presented in Fig. 16. A high agreement can be observed between the experimental and analytical results - especially for the $2 \mathrm{D}$ analytical with the effect of end-winding contribution. It can be clearly seen that the currents in the strands have different amplitude and phase that eventually leads to uneven AC loss distribution between those strands. It should be mentioned that despite the using of sinusoidal current source high order harmonics exist in the spectrum of the supplied current. For this reason the first 30 harmonics of the actual supplied current were used for analytical simulation. The supplied current THD is $0.43 \%, 0.92 \%$ and $1.64 \%$ for $500 \mathrm{~Hz}, 1000 \mathrm{~Hz}$ and $2000 \mathrm{~Hz}$ respectively.

Knowing the measured and simulated current through each strand as well as the strands resistance the AC ohmic loss can be easily evaluated as $P_{n}=I_{n}^{2} R_{n}$, where $P_{n}$ is the measured loss in $n^{\text {th }}$ strand; $I_{n}$ is the measured current through $n^{\text {th }}$ strand and $R_{n}$ is the measured resistance of $n^{\text {th }}$ strand. The comparison of the losses generated in each strand at $1 \mathrm{kHz}$ of fundamental frequency and 2 Arms total current is shown in Fig. 17. The strands with lower index (strand 1 and 2) are placed close to the slot-opening and have lower inductance compared to the strands which are placed deeper in the slot (strand 3 and 4). As the results show, the current amplitude and the AC losses of the lower inductance strands is higher as shown in Fig. 17. For the presented case the measured AC loss for the $1^{\text {st }}$ strand at $1 \mathrm{kHz}$ is $\sim 41.9 \mathrm{~mW}$ while for the $4^{\text {th }}$ one is $\sim 6.1 \mathrm{~mW}$ which is about 6.9 times lower.

The experimental and modeled total AC Ohmic loss comparison for the investigated coil at the frequency of $500 \mathrm{~Hz}$, $1000 \mathrm{~Hz}$ and $2000 \mathrm{~Hz}$ is presented in Fig. 18. The difference between the measured AC loss and the proposed method for the coil is in the range from $2.5 \%$ to $6.8 \%$ however, by taking into account the additional self and mutual inductance of the end- winding the accuracy of the model is falling into the range from $2.1 \%$ to $3.5 \%$ depending on the frequency.

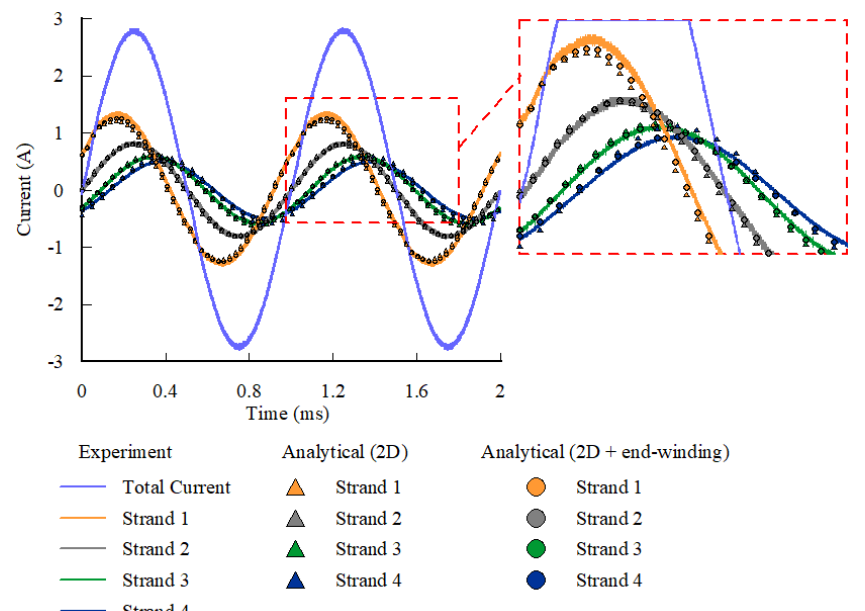

Fig. 16 Current waveform comparison (Total current - 2 Arms, $1 \mathrm{kHz}$ )

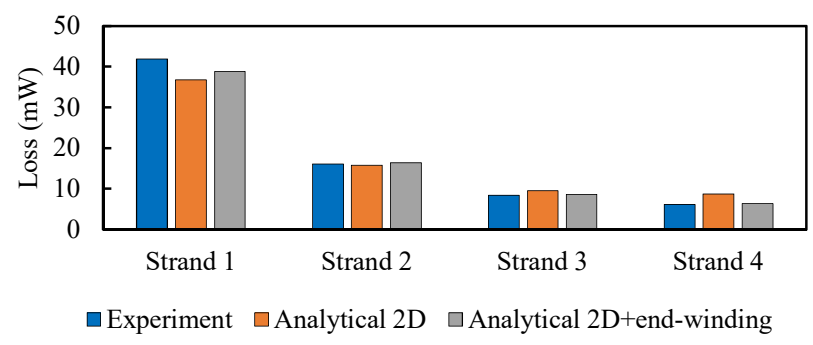

Fig. 17 Strand to strand loss comparison at $2 \mathrm{Arms}, 1 \mathrm{kHz}$

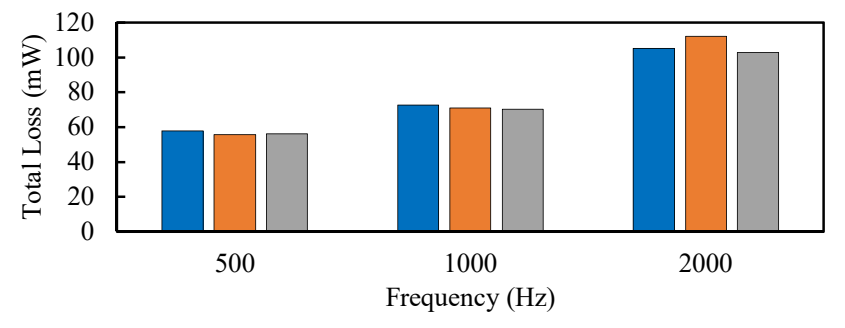

$\square$ Experiment $\square$ Analytical 2D $\square$ Analytical 2D+end-winding

Fig. 18 Comparison of experimental results and analytical prediction for AC loss in the coil at different current frequency

\section{CONCLUSIONS}

The proposed analytical methodology allows modelling of circulating current loss in the parallel paths of the windings of synchronous electrical machines with permanent magnets. The approach is based on the direct solving of Laplace's and Poisson's equations in the subdomains of the active parts of machine and subsequent solving of a system of ordinary differential equations for an equivalent circuit of machine winding. The methodology described in this work was implemented for PMSM with Halbach array. The model takes into account the slot geometry including the slot opening dimensions, the amount of PM segments per pole pitch, the direction of magnetization of PM segments as well as position of the conductors in the slots.

The experimental data and the comparison with FEM are in line with the analytical modelling results. The deviation of the 
modelled AC losses from the measured ones is in the range from $2.5 \%$ to $6.8 \%$ without considering the end-winding and from $2.1 \%$ to $3.5 \%$ when taking into account an additional self and mutual inductance of the end-winding.

The proposed model is faster than FEM and was developed to use for optimisation of strands arrangement in the slots of electrical machines. For the presented case study the model allows reducing the simulation time from $30 \mathrm{~min}$ to $4.5 \mathrm{~min}$ keeping the accuracy within the range $1-2 \%$ compared to linear FEM and about $13 \%$ compared to non-linear FEM.

\section{ACKNOWLEDGMENT}

The authors would like to acknowledge the PEMC group technicians team of the University of Nottingham, in particular: John Hinchliffe, Kevin Last, Ian Medley, Guy Thompson, Matthew Cooper for technical support in building motorette as well as $\mathrm{PhD}$ student Andrea Stratta for assistance in measurements.

\section{REFERENCES}

[1] D. Bauer, P. Mamuschkin, H.-C. Reuss and E. Nolle, "Influence of parallel wire placement on the AC copper losses in electrical machines," in IEEE International Electric Machines \& Drives Conference (IEMDC), Coeur d'Alene, ID, USA, 2015.

[2] A. Lehikoinen, N. Chiodetto, E. Lantto, A. Arkkio and A. Belahcen, "Monte Carlo Analysis of Circulating Currents in Random-Wound Electrical Machines," IEEE Transactions on Magnetics, vol. 52, no. 8, 2016.

[3] A. Lehikoinen, N. Chiodetto, A. Arkkio and A. Belahcen, "Improved sampling algorithm for stochastic modelling of random-wound electrical machines," The Journal of Engineering, vol. 2019, no. 17, pp. 3976 3980, 2019

[4] K. Yamazaki, T. Furuhashi, H. Yui, H. Ohguchi, H. Ohguchi, S. Imamori and M. Shuto, "Analysis and Reduction of Circulating Current Loss of Armature Wires in Permanent Magnet Synchronous Machines," IEEE Transactions on Industry Applications, vol. 55, no. 6, pp. 5888 - 5896, 2019.

[5] W. Chen, Y. Liu, J. Islam and D. Svechkarenko, "Strand-level finite element model of stator AC copper losses in the high speed machines," in XXth International Conference on Electrical Machines, Marseille, France, 2012.

[6] F. Birnkammer, J. Chen, D. B. Pinhal and D. Gerling, "Influence of the Modeling Depth and Voltage Level on the AC Losses in Parallel Conductors of a Permanent Magnet Synchronous Machine," IEEE Transactions on Applied Superconductivity, vol. 28, no. 3, 2018 .

[7] A. Bardalai, D. Gerada, D. Golovanov, Z. Xu, X. Zhang, J. Li, H. Zhang and C. Gerada, "Reduction of Winding AC Losses by Accurate Conductor Placement in High Frequency Electrical Machines," IEEE Transactions on Industry Applications, vol. 56, no. 1, pp. 183 - 193, 2020 .

[8] Y. Liang, X. Bian, L. Yang and L. Wu, "Numerical calculation of circulating current losses in stator transposition bar of large hydrogenerator," IET Science, Measurement \& Technology, vol. 9, no. 4, pp. $485-491,2015$.

[9] Y. Liang, L. Wu and C. Wang, "Influence of Void Transposition Structure on the Leakage Magnetic Field and Circulating Current Loss of Stator Bars in Water-Cooled Turbo-Generators," IEEE Transactions on Industrial Electronics, vol. 63, no. 6, pp. 3389 - 3396, 2016.

[10] M. Fujita, Y. Kabata, T. Tokumasu, K. Nagakura, M. Kakiuchi and S. Nagano, "Circulating Currents in Stator Coils of Large Turbine Generators and Loss Reduction," IEEE Transactions on Industry Applications, vol. 45, no. 2, pp. 685 - 693, 2009.

[11] F. Chai, Z. Li and Y. Yu, "Analysis of AC Losses in High-Speed Permanent Magnet Motors Based on the Equivalent Modeling Method," in 2018 XIII International Conference on Electrical Machines (ICEM), Alexandroupoli, Greece, 2018.

[12] C. Roth, F. Birnkammer and D. Gerling, "Analytical Model for AC Loss Calculation Applied to Parallel Conductors in Electrical Machines," in 2018 XIII International Conference on Electrical Machines (ICEM) Alexandroupoli, Greece, 2018.

[13] T. L. a. S. Mezani, "2-D Exact Analytical Model for Surface-Mounted Permanent-Magnet Motors With Semi-Closed Slots," IEEE Transactions on Magnetics, vol. 47, no. 2, pp. 479 - 492, 2011.

[14] D. Golovanov and C. Gerada, "An Analytical Subdomain Model for Dual-Rotor Permanent Magnet Motor With Halbach Array," IEEE Transactions on Magnetics, vol. 55, no. 12, 2019.

[15] Y. Oner et al, "Analytical On-Load Subdomain Field Model of Permanent-Magnet Vernier Machines," IEEE Transactions on Industrial Electronics, vol. 63, no. 7, pp. 4105 - 4117, 2016.

[16] A. Bardalai, Z. Xu, J. Li, D. Gerada, C. Gerada, D. Golovanov and H. Zhang, "The influence of Strands and Bundle - level arrangements of magnet wires on AC losses in the winding of High - Speed Traction Machine," in 201821 st International Conference on Electrical Machines and Systems (ICEMS), Jeju, Korea, 2018.

[17] E. Preci and e. al, "Experimental Statistical Method Predicting AC Losses on Random Windings and PWM Effect Evaluation," IEEE Transactions on Energy Conversion, vol. 10.1109/TEC.2020.3040265, no. Early Access, 2020.

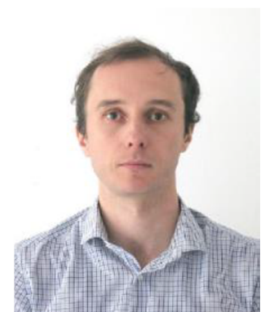

Dmitry Golovanov received the Ph.D. degree in superconducting electrical machines from Moscow Aviation Institute, Moscow, Russia, in 2011.,He has an experience of working in industry as a Researcher in VNIIEM Corporation JSC, Russia, in the field of design of electrical machines and in Samsung SDI, South Korea, in the field of Li-ion batteries. He is currently a Research Fellow in the University of Nottingham, Nottingham, UK. His main research interests include high power density electric machines for aerospace and automotive industry application, and superconducting electrical machines.

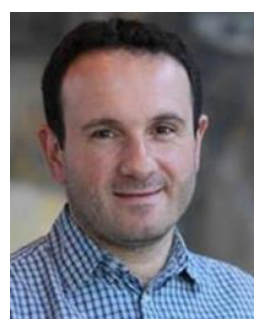

Chris Gerada (SM'12) is an Associate Pro-Vice-Chancellor for Industrial Strategy and Impact and Professor of Electrical Machines. His principal research interest lies in electromagnetic energy conversion in electrical machines and drives, focusing mainly on transport electrification. He has secured over £20M of funding through major industrial, European and UK grants and authored more than 350 referred publications. He received the Ph.D. degree in numerical modelling of electrical machines from The University of Nottingham, Nottingham, U.K., in 2005. He subsequently worked as a Researcher with The University of Nottingham on high-performance electrical drives and on the design and modelling of electromagnetic actuators for aerospace applications. In 2008, he was appointed as a Lecturer in electrical machines; in 2011, as an Associate Professor; and in 2013, as a Professor at The University of Nottingham. He was awarded a Research Chair from the Royal Academy of Engineering in 2013. Prof. Gerada served as an Associate Editor for the IEEE Transactions on Industry Applications and is the past Chair of the IEEE IES Electrical Machines Committee. 